\title{
One is okay, more is better? Pharmacological aspects and safe limits of nutritional supplements
}

\author{
Pamela Mason \\ The Rectory, Grosmont, Monmouthshire NP7 8LW, UK
}

\begin{abstract}
The use of vitamins, minerals and other supplements has increased considerably during recent years. In the National Diet and Nutrition Survey of British adults aged 19-64 years $40 \%$ of those surveyed were taking supplements. In 2005 sales of dietary supplements in the UK were approximately $£ 325.7 \times 10^{6}$ in 'bricks and mortar' shops (excluding health food shops). The physiological effects of vitamins and minerals in amounts approximating to the UK reference nutrient intake or the EU RDA are well understood in terms of reducing the risk of micronutrient deficiency. However, the effects of vitamins, minerals and other supplements in larger amounts have attracted much attention in recent decades, and these effects, some of which may be pharmacological, are not as well categorised. Some of these effects are beneficial, some are not. Although vitamins and minerals and other supplements are generally safe at higher doses, there are some safety issues that are relevant in the context of the wide availability of supplements without a doctor's prescription. Thus, several authorities throughout the world have established upper limits (UL) for the intake of vitamins and minerals, and the EU is in the process of setting maximum permitted levels (MPL) for vitamins and minerals in food supplements. The present paper discusses the potential benefits and safety issues relating to the use of supplements at doses higher than the RDA. The rationale for the establishment of UL is also discussed, explaining the differences between the values set by different authorities and the expected guidance and legislation from the European Commission on MPL for vitamins and minerals in food supplements.
\end{abstract}

Nutritional supplements: Benefits: Safety issues

Food supplements are defined as concentrated sources of nutrients or other substances (e.g. fish oils) with a physiological or nutritional effect, marketed in dose forms such as tablets, capsules, powders and liquids, designed to be taken in unit quantities to supplement the diet ${ }^{(1)}$. These products have become increasingly popular during recent decades. Surveys show that $40 \%$ of British adults take them $^{(2)}$, and UK sales in 'bricks and mortar' shops amounted to $£ 325.7 \times 10^{6}$ in 2005 , multivitamins and fish oils being the most popular ${ }^{(3)}$. Food supplements are taken for many reasons, mostly as an insurance policy to make up for a poor diet and/or to promote optimal health and fitness. Supplements are also used in an attempt to enhance sports and athletic performance and prevent or manage minor ailments such as colds and skin, hair and nail problems, as well as more distressing conditions such as premenstrual syndrome and menopausal symptoms and diseases such as arthritis, CVD, cataract and age-related macular degeneration.

\section{One is okay: moderate multivitamins}

A substantial proportion of multivitamins sold on the UK 'high street' contain amounts of vitamins and minerals approximating to the RDA. (The EU RDA (rather than the UK dietary reference values) is the reference value used to compare amounts of vitamins and minerals on the labels of food supplements in the UK and throughout the EU.) Such products are safe, and given that recent UK National Diet and Nutrition Surveys ${ }^{(2,4-6)}$ have shown that some population groups are at risk from marginal intakes, a 'moderate' 'one-a-day' multivitamin-mineral supplement may be beneficial. Although supplements are not a

\footnotetext{
Abbreviations: EVM, Expert Vitamin and Mineral Group; LOAEL, lowest observed adverse effect level; MPL, maximum permitted levels; MSL, maximum safe levels; NOAEL, no observed adverse effect level; PSI, population safety index; UL, upper levels.

Corresponding author: Dr Pamela Mason, email pamelamason@apotek.org.uk
} 
substitute for a poor diet, evidence shows they can help to reduce nutritional gaps.

Studies in adults have shown that supplement use can make an important contribution to vitamin and mineral intake. The National Diet and Nutrition Survey in British adults has found that supplement users have higher intakes of vitamins and minerals and are less likely to have intakes below the reference nutrient intake than non-supplement users $^{(7)}$. Similar findings have been reported for Ireland ${ }^{(8)}$, Germany $^{(9,10)}$, the USA ${ }^{(11)}$ and Canada ${ }^{(12)}$. Food supplements have also been shown to make a substantial contribution to the intakes of vitamins and minerals in toddlers $^{(13,14)}$ and teenagers ${ }^{(15-18)}$. Several studies ${ }^{(19-21)}$ have also shown that supplementation with vitamins and minerals can improve plasma levels of micronutrients and reduce the prevalence of suboptimal plasma concentrations.

The use of multivitamins has also been associated with reduced risk of chronic disease in some, but not all, studies. Evidence from observational studies suggests a reduced risk of CVD in users of multivitamins ${ }^{(22,23)}$. In the Cancer Prevention Study II cohort past multivitamin use ( $>10$ years before enrolment), but not recent use $(<10$ years before enrolment) was found to be associated with modestly-reduced risk of colo-rectal cancer ${ }^{(24)}$, but a small increase in prostate cancer ${ }^{(25)}$. In the Health Professionals' Follow-up Study men who reported folate consumption from multivitamins for $>10$ years were found to have a $25 \%$ reduction in colon cancer risk ${ }^{(26)}$, and in the Nurses' Health Study women who reported multivitamin use (with folate) for $\geq 15$ years were found to have a $75 \%$ reduction in colo-rectal cancer risk ${ }^{(27)}$. However, in a pooled analysis of eight prospective studies no significant association between the use of multivitamins and specific vitamin supplements and lung cancer risk was found ${ }^{(28)}$.

The use of multivitamin supplements has also been associated with reduced risk of cataract ${ }^{(29,30)}$. However, evidence for a benefit of multivitamins in the prevention of infection is weak and conflicting, as confirmed by two systematic reviews-meta-analyses, one in the elderly ${ }^{(31)}$ and one in adults of all ages ${ }^{(32)}$.

Such benefits observed for consumers of multivitamin supplements may result from their concerns about health and their attempts to live healthier lifestyles. It is well recognised that individuals who take supplements may be the ones who least need them. Intakes of fruit and vegetables $^{(33)}$ and micronutrients from food ${ }^{(8,15,18)}$ have been found to be higher in supplement users, although one study has found no difference ${ }^{(13)}$. In a Canadian study $\mathrm{Ca}$ and vitamin D intakes from food were actually lower in supplement users than in non-supplement users ${ }^{(12)}$, possibly because of lower dairy consumption in those taking supplements.

\section{More is better? Higher levels of intake}

Although a moderate-'RDA' multivitamin supplement is safe and also potentially beneficial for some population groups, some individuals choose to take combinations of several products (e.g. multivitamins, single vitamins or minerals, antioxidants, products marketed for specific periods of life, such as the menopause, and long-chain fatty acids) in an attempt to promote 'optimal health' and prevent or manage various conditions. In addition, the UK has traditionally had a liberal safety-based approach to the use and sale of vitamins and minerals, and several highdose products are available on the UK market. Higher-dose products, defined as those with a daily dose at or above the doses recommended by the UK Expert Vitamin and Mineral Group $(\mathrm{EVM})^{(34)}$ have been estimated to represent $12-15 \%$ ( $£ 25-33 \times 10^{6}$ per annum) of the total UK vitamin and mineral supplement market ${ }^{(35)}$.

So, what might be the benefits of higher intakes of vitamins and minerals? If one is okay, is more better? There is clear epidemiological evidence of links between micronutrient status and the risk of chronic disease ${ }^{(36)}$, and indications that some nutrients (e.g. antioxidant substances) can beneficially influence biomarkers of chronic disease. These findings have prompted the search for evidence of efficacy for specific supplements from controlled intervention trials.

\section{$B$-vitamins}

Neural-tube defects. There is abundant evidence that folic acid protects against the development of neuraltube defects, specifically anencephaly and spina bifida, as described in a recent review ${ }^{(37)}$. Supplementation of folic acid at amounts exceeding the RDA is recommended for all women capable of becoming pregnant and during the first 12 weeks of pregnancy. The recommended intakes are $4 \mathrm{mg} / \mathrm{d}$ for women at high risk (by virtue of a previous neural-tube defect pregnancy outcome or those with epilepsy) and $0 \cdot 4 \mathrm{mg} / \mathrm{d}$ for all other women.

$C V D$. Hyperhomocysteinaemia is associated with increased risk of CVD, and supplementation with folic acid (with or without vitamins $B_{6}$ and $B_{12}$ ) results in reduced concentrations of homocysteine, as confirmed by meta-analyses ${ }^{(38,39)}$. By contrast, results from trials with B-vitamin supplements that examined definitive clinical cardiovascular outcomes have been disappointing. However, supplementation trials have largely been conducted in patients with pre-existing CVD and results from secondary prevention studies may not reflect the outcome in healthy individuals taking supplements. For example, the two-year Vitamin Intervention for Stroke Prevention Trial in patients with non-disabling cerebral infarction has found no difference between high-dose B-vitamins (including $2.5 \mathrm{mg}$ folic acid/d) and a low dose (including $20 \mu \mathrm{g}$ folic $\mathrm{acid} / \mathrm{d})$ in relation to stroke, coronary event or death ${ }^{(40)}$. Furthermore, the Heart Outcomes Prevention Evaluation Trial has shown no benefit with folic acid $(2.5 \mathrm{mg} / \mathrm{d})$, vitamin $\mathrm{B}_{6}(50 \mathrm{mg} / \mathrm{d})$ and vitamin $\mathrm{B}_{12}(1 \mathrm{mg} / \mathrm{d})$ among patients with pre-existing CVD or diabetes ${ }^{(41)}$, while the Norwegian Vitamin Trial has found that the combination of vitamin $\mathrm{B}_{6}$, vitamin $\mathrm{B}_{12}$ and folic acid decreases plasma homocysteine but has no demonstrable benefit on other CVD-related outcomes in patients who have had a myocardial infarction $^{(42)}$. Data from the Women's Antioxidant and Folic Acid and Cardiovascular Study (CM Albert, NR Cook, JM Gaziano, SS Bassuk, E Zaharris, JG MacFayden, 
D Danielson, M Van Denburgh and JE Buring, unpublished results), are similar to those from the Heart Outcomes Prevention Evaluation Trial and the Norwegian Vitamin Trial in that among women with, or at increased risk for, $\mathrm{CVD}$ treatment with folic acid, vitamin $\mathrm{B}_{6}$ and vitamin $\mathrm{B}_{12}$ was not found to be associated with differences in cardiovascular-related death, myocardial infarction, stroke or revascularisation through a mean of a 7-year follow-up compared with placebo.

However, it may yet to be too early to abandon the idea that folic acid and other B-vitamins can reduce risk of CVD. Indeed, the B-Vitamin Treatment Trialists' Collaboration has recently reviewed the design and statistical power of twelve randomised trials assessing the effects of lowering homocysteine with B-vitamin supplements on risk of $\mathrm{CVD}^{(43)}$. They have concluded that the individual trials may not have involved a sufficient number of vascular events nor have been of sufficient duration to have produced a good chance on their own of detecting plausible effects of homocysteine lowering on risk of CVD. However, the combined analysis of these trials, which will be available within a few years, should have adequate power to determine whether lowering homocysteine reduces the risk of cardiovascular events.

Other conditions. Evidence exists of a link between low folate status and cancer, particularly colon cancer and cervical cancer ${ }^{(4)}$. However, controlled trials are needed to determine whether supplementation reduces risk. Bvitamins have also been investigated in Alzheimer's disease and depression, and a meta-analysis of four randomised controlled intervention trials has provided no evidence that folic acid supplementation, with or without vitamin $\mathrm{B}_{12}$, has a beneficial effect on cognitive function or mood in cognitively-impaired older subjects ${ }^{(45)}$. More recently, in a trial that randomised 818 participants to $800 \mu \mathrm{g}$ folic acid/d or placebo for 3 years the folic acid group were reported to show a better 3-year change in memory, sensorimotor speed and information processing speed than the placebo group ${ }^{(46)}$. A systematic review of three randomised controlled trials involving folate supplementation suggests that folate may have a potential role as a supplement to other treatment for depression ${ }^{(47)}$, but has concluded that further trials are needed before supplementation can be recommended for this group of patients.

\section{Vitamin $C$}

Vitamin $\mathrm{C}$ is an antioxidant that also inhibits the formation of carcinogenic nitrosamines from dietary nitrates. It might therefore be expected to be protective against the development of CVD and cancer. Clinical trials have evaluated the effects of vitamin $\mathrm{C}$ supplements in the development of these diseases but evidence is inconsistent.

High doses of vitamin $\mathrm{C}$ are popularly recommended for the prevention and treatment of the common cold. A review of thirty trials by the Cochrane Collaboration has concluded that long-term daily supplementation with large doses of vitamin $C$ does not appear to prevent colds, but there is a modest benefit in terms of reducing the duration of cold symptoms from the ingestion of high doses ${ }^{(48)}$. An update of this review has added that vitamin $\mathrm{C}$ could be justified in individuals exposed to brief periods of severe physical exercise and/or cold environments and that regular vitamin $\mathrm{C}$ supplementation could reduce the duration and severity of colds. A more-recent randomised doubleblind 5-year controlled trial has found that vitamin C supplementation at $500 \mathrm{mg} / \mathrm{d}$ reduces the frequency, but not the duration or severity, of the common cold in comparison with a dose of $50 \mathrm{mg} / \mathrm{d}^{(49)}$. However, the authors urged caution in interpreting this study because of a variety of limitations, including a large number of subject dropouts.

\section{Vitamin D}

Vitamin D deficiency continues to be more common than was thought some years ago, with a high prevalence in inner city areas among Afro-Caribbeans and Asians, particularly women ${ }^{(50)}$. Individuals with inadequate sunlight exposure, especially older adults, young children and pregnant women may benefit from vitamin D supplementation to prevent deficiency. A suitable dose for adults in this category is generally $10 \mu \mathrm{g} / \mathrm{d}$.

However, lack of vitamin D is increasingly associated with a range of conditions, such as osteoporosis, falls, cancer, CVD, diabetes mellitus and poor immune function, with the possibility that supplementation could be protective. Evidence from clinical intervention trials to date is strongest for benefit of vitamin $\mathrm{D}$ in protecting against fracture, but findings are conflicting. Two meta-analyses have found that vitamin $\mathrm{D}$ in a dose of approximately $20 \mu \mathrm{g} / \mathrm{d}$ prevents both vertebral and non-vertebral fractures in older adults ${ }^{(51,52)}$. However, these effects have not been confirmed in more recent trials. An extension of the mostrecent meta-analysis ${ }^{(52)}$ to include four further trials ${ }^{(53)}$ has concluded that high-dose, but not low-dose, vitamin D is effective in reducing fracture risk in the institutionalised elderly, but not in the general population. Two further meta-analyses have found that vitamin D reduces the risk of falls ${ }^{(54,55)}$, which might be expected to reduce the risk of fall-related fractures.

\section{Vitamin $E$}

Vitamin E has both antioxidant and anti-inflammatory properties and has been one of the most-widely-studied vitamins in relation to the use of supplementary doses in excess of the RDA. Claims have been made for a wide variety of benefits of vitamin $\mathrm{E}$ supplementation, with most research attention given to CVD. The literature abounds with evidence that vitamin $\mathrm{E}$ inhibits smooth muscle proliferation, platelet aggregation, monocyte endothelial adhesion, LDL oxidation and improves vascular function, as exemplified in two recent reviews ${ }^{(56,57)}$. Unfortunately, many vitamin $\mathrm{E}$ studies have been carried out in tissue cultures rather than in supplemented human subjects, so the health benefits of these findings are unclear.

Several observational studies have examined the influence of vitamin E supplementation in CVD. In the Nurses' Health Study consumption of vitamin E supplements for $>2$ years was found to be associated with a $41 \%$ lower 
relative risk of major coronary disease ${ }^{(58)}$. Similar results were obtained in an observational study in male health professionals, for whom there was a $37 \%$ lower relative risk of $\mathrm{CHD}$ in those who took vitamin $\mathrm{E}$ supplements in doses of $\geq 100 \mathrm{mg}$ daily for $>2$ years $^{(59)}$.

However, clinical trials evaluating supplements of vitamin $\mathrm{E}$ have not consistently demonstrated protection against CVD. The first clinical trial to test the efficacy of vitamin $\mathrm{E}$ in heart-attack prevention was the Cambridge Heart Antioxidant Study, which has shown that vitamin E reduces the 1-year rate of non-fatal myocardial infarction, but causes no reduction in cardiovascular-related mortality $^{(60)}$. Extended follow up of the Heart Outcomes Prevention Evaluation Study has actually suggested an increased risk of heart failure in the vitamin E-supplemented group ${ }^{(61)}$. More than 200 trials using vitamin E supplements have been carried out and a recent review and meta-analysis claims that vitamin $\mathrm{E}$ has neither benefit nor $\operatorname{harm}^{(62)}$.

With hind sight, clinical trials of vitamin E, like those with other vitamin supplements, have been overly optimistic in their expectation that a vitamin could reduce the risk of multifactorial disease and provide benefit equal to or beyond that of pharmaceutical medication. However, it is noteworthy that in most clinical trials biomarkers were not used nor were oxidative stress and lipid peroxidation markers of plasma vitamin $\mathrm{E}$ concentrations measured.

\section{Antioxidants}

CVD. Clinical trials involving antioxidant supplements (e.g. combinations of $\beta$-carotene, vitamin $\mathrm{C}$ and vitamin $\mathrm{E}$ ) and CVD have again mainly been disappointing. The Finnish Alpha-Tocopherol Beta-Carotene Cancer Prevention Study of heavy smokers has found no reduction in CHD morbidity or mortality during 5-8 years treatment with vitamin E ( $50 \mathrm{mg}$ daily) and $\beta$-carotene ( $20 \mathrm{mg}$ daily). Significantly more deaths were found in the $\beta$-carotene group than in the placebo group ${ }^{(63)}$ and during the 6-year post-trial follow up $\beta$-carotene increased the post-trial risk of first-ever non-fatal myocardial infarction ${ }^{(64)}$. The UK Heart Protection Study involving adults with CVD or diabetes also found no significant differences in all-cause mortality, non-fatal myocardial infarction, coronary death or stroke with antioxidant supplementation $(\mathrm{mg} / \mathrm{d}$; vitamin E 600 , vitamin C $250, \beta$-carotene 20$)^{(65)}$. A trial in postmenopausal women with coronary disease has found that supplementation with vitamin E $266.8 \mathrm{mg}$ twice daily and vitamin C $500 \mathrm{mg}$ twice daily does not retard atherosclerosis $^{(66)}$. Results from the Supplementation en Vitamines et Mineraux Antioxydants Study have suggested that a combination of antioxidants (mg/d: vitamin C 120 , vitamin $\mathrm{E} 30, \beta$-carotene $6, \mathrm{Se} 0 \cdot 1, \mathrm{Zn} 20$ ) over an average of $7 \cdot 2$ years has no beneficial effects on carotid atherosclerosis and arterial stiffness ${ }^{(67)}$ or risk of hypertension $^{(68)}$. A meta-analysis evaluating antioxidants has confirmed no benefit of vitamin $\mathrm{E}$ supplementation on all-cause mortality, cardiovascular mortality or cerebrovascular accident, and has shown that $\beta$-carotene is associated with a slight increase in all-cause mortality and cardiovascular death $^{(69)}$. An extensive US review has also suggested that there is no benefit of supplements containing vitamin $\mathrm{E}$ or vitamin $\mathrm{C}$ (either alone or in combination) on either CVD or all-cause mortality ${ }^{(70)}$. More recently, a further meta-analysis that included sixty-eight randomised controlled trials with 232606 participants has found that treatment with $\beta$-carotene, vitamin $A$ and vitamin $\mathrm{E}$ singly or combined may increase mortality ${ }^{(71)}$.

Cancer. In relation to cancer, intervention studies involving antioxidant supplements have again been conflicting. While the Chinese Linxian Trial has found that combined daily doses of $\beta$-carotene, vitamin $\mathrm{E}$ and Se over 5 years are linked with a $13 \%$ reduction in cancer deaths and a $9 \%$ reduction in all-cause mortality ${ }^{(72)}$, the AlphaTocopherol Beta-Carotene Cancer Prevention Study has found no reduction in the incidence of lung cancer among male smokers after 5-8 years of supplementation with vitamin $\mathrm{E}$ or $\beta$-carotene $^{(73)}$. Indeed, the incidence of lung cancer and overall death rate were found to be increased in the group receiving $\beta$-carotene. More recent data from this study has shown no reduction in the risk of either colorectal or gastric cancer. The Polyp Prevention Study has also found no evidence that antioxidant supplements reduce the risk of colo-rectal adenomas ${ }^{(74)}$. A 3-year trial among 1980 subjects in Venezuela (in a population with a high risk of gastric cancer) has found that supplementation with vitamin $\mathrm{C}, \mathrm{E}$ and $\beta$-carotene does not influence progression rates of precancerous gastric lesions compared with placebo ${ }^{(75)}$. However, other studies have shown that low-dose antioxidant supplementation is associated with reduced cancer incidence and all-cause mortality in men ${ }^{(76)}$, and supplemental $\beta$-carotene and vitamin $\mathrm{E}$ is associated with reduced risk of prostate cancer ${ }^{(77)}$. Two systematic reviews have found no evidence of benefit for antioxidant supplements in the prevention of cancer $^{(78)}$.

Eye disease. Antioxidant supplements have also been examined in relation to eye disease. Evidence for benefit of antioxidant supplements in cataract is limited, with no significant effect on cataract development and progression in the Age Related Eye Disease Study ${ }^{(79)}$, although there was a small positive effect of supplements in the Roche European American Cataract Trial ${ }^{80,81)}$ The Age Related Eye Disease Study also evaluated the effect of antioxidant vitamins combined with $\mathrm{Zn}(80 \mathrm{mg} / \mathrm{d})$ and $\mathrm{Cu}(2 \mathrm{mg} / \mathrm{d})$ on age-related macular degeneration. Both $\mathrm{Zn}$ alone and antioxidants plus $\mathrm{Zn}$ were found to reduce the odds of developing advanced age-related macular degeneration in the higher-risk group, but showed no benefits at other stages of the disease.

\section{Calcium}

Bone health. Many intervention trials have investigated the influence of Ca supplementation (with or without vitamin D) on bone density and fracture risk. A recent meta-analysis has found that children taking $\mathrm{Ca}$ supplements show only small improvements in bone density, which are unlikely to reduce the risk of fracture in either childhood or later adult life ${ }^{(82)}$. However, many of the included trials involved children who were $\mathrm{Ca}$ replete. In 
post-menopausal women there is evidence from metaanalysis that $\mathrm{Ca}$ supplementation can slow bone loss ${ }^{(83)}$. Moreover, there is strong evidence that $\mathrm{Ca}$ in combination with vitamin $\mathrm{D}$ decreases the risk for hip and non-vertebral fracture in post-menopausal women ${ }^{(84-86)}$. The National Institute for Health and Clinical Excellence is currently developing guidelines relating to osteoporosis that will look at prescribing vitamin $\mathrm{D}$ and $\mathrm{Ca}$ as an intervention.

Other conditions. Studies have demonstrated that $\mathrm{Ca}$ supplements may reduce blood pressure, protect against colon cancer and reduce menstrual pain. A Cochrane review has concluded that $\mathrm{Ca}$ supplementation is associated with small $(2.5(95 \%$ CI $4.5,0.6) \mathrm{mmHg})$, but significant reduction in systolic but not diastolic blood pressure $^{(87)}$. In the Calcium Polyp Prevention Study Ca $(1200 \mathrm{mg} / \mathrm{d})$ was found to have a more pronounced antineoplastic effect on advanced colo-rectal lesions than on other types of polyps ${ }^{(88)}$. A recent Cochrane review has concluded that evidence from two randomised controlled trials suggests that $\mathrm{Ca}$ supplementation might contribute to a moderate extent to the prevention of colo-rectal adenomatous polyps, but that this outcome does not constitute sufficient evidence to recommend the general use of $\mathrm{Ca}$ supplements to prevent colo-rectal cancer ${ }^{(89)}$. Two trials have shown a benefit of Ca supplementation (1000$1200 \mathrm{mg} / \mathrm{d})$ in premenstrual and menstrual pain ${ }^{(90,91)}$. There is increasing interest in the possibility that $\mathrm{Ca}$ may have a role in the maintenance of body weight. However, a recent randomised controlled trial involving $\mathrm{Ca}$ supplementation ( $1000 \mathrm{mg}$ daily) found no difference in body weight and fat-free mass between a supplemented group of women and the placebo group, but there was a trend towards loss of weight in the supplemented group, which the authors suggest could be consistent with a small effect $^{(92)}$.

\section{Selenium}

Se supplementation has also been evaluated in relation to cancer end points. The US Nutritional Prevention of Cancer Trial was the first double-blind placebo-controlled trial in a Western population designed to test the hypothesis that Se supplementation could reduce the risk of cancer ${ }^{(93)}$. Involving 1312 individuals with a history of nonmelanoma skin cancer, the trial found that $200 \mu \mathrm{g} \mathrm{Se} / \mathrm{d}$ was associated with a $37 \%$ reduction in total cancer incidence, $63 \%$ fewer cancers of the prostate, $58 \%$ fewer cancers of the colon and $46 \%$ fewer cancers of the lung. No significant differences were found in the incidence of basalcell carcinoma or squamous-cell carcinoma, and there were more cases of breast cancer and leukaemia lymphoma in the Se group, but these differences were not significant. Further analysis has continued to show a protective effect of Se on the overall incidence of prostate cancer, although the effect was restricted to those with lower baseline prostate-specific antigen levels and plasma Se concentrations $^{(94)}$. A systematic review and meta-analysis of sixteen studies has confirmed that Se supplementation may reduce the risk of prostate cancer. Further large randomised trials, which are ongoing, will help to throw more light on this issue $^{(95)}$.

\section{Safety of high intakes}

Some nutrients (e.g. vitamins A, D and $\mathrm{B}_{6}$ and $\mathrm{Se}$ ) are well known to cause toxicity if consumed in excessive amounts. For vitamin A the intake at which toxic effects occur is about ten to twelve times the reference nutrient intake for adults, but only about three times that for infants and pregnant women. Vitamin A has received particular attention because of the possibility that high intakes of retinol could increase the risk of osteoporosis and fracture. Since 1998 four cross-sectional studies ${ }^{(96-99)}$ and seven cohort studies $^{(100-106)}$ have investigated the association between retinol and bone health. The cross-sectional studies have generally shown no association between vitamin A status or intake and risk to bone health. The cohort studies have reported mixed effects; some have found that excess vitamin A may increase the risk of hip fracture, while others have found no risk. One study has demonstrated benefit to bone density. All these studies are complicated by the presence of other nutrients in the diets of those studied, differences in vitamin A intake between study populations and difficulties in assessing vitamin A intake. Whether high intakes of retinol do have a deleterious influence on bone health is therefore unclear.

Concern about overdosing on dietary supplements is nothing new. However, the publicised benefits of taking supplements and the huge variety of products on the market, together with the knowledge that $\leq 50 \%$ of the populations of Western countries take them has increased the safety concerns in more recent years. These concerns have encouraged several authorities worldwide to establish safe upper levels (UL) for vitamins and minerals.

\section{Establishment of upper levels}

In the UK the food supplement industry began researching the concept of safe UL in the mid 1980s, and in October 1997 the European Federation of Health Product Manufacturers and the Council for Responsible Nutrition established safe UL for both long-term and short-term consumption of twenty-five vitamins and minerals ${ }^{(107)}$. The approach they used was to base the UL well below the level at which a significant adverse effect had been reported in the literature. Subsequently, several other authorities in the USA ${ }^{(108-111)}$, Europe ${ }^{(112)}$, the $\mathrm{UK}^{(34)}$ and Australia and New Zealand ${ }^{(113)}$ have set safe UL for vitamins and minerals.

\section{Nutrient risk assessment}

The model for estimation of the UL recommended in a recent joint report of the $\mathrm{WHO}$ and $\mathrm{FAO}^{(114)}$ is based on nutrient risk assessment, which is illustrated in Fig. 1. The UL set by the USA, Europe, the UK and Australia and New Zealand have also been based on this model (albeit with some differences in methodological detail).

\section{Hazard identification and hazard characterisation}

The process begins with the identification of adverse health effects associated with the nutrient concerned and makes 


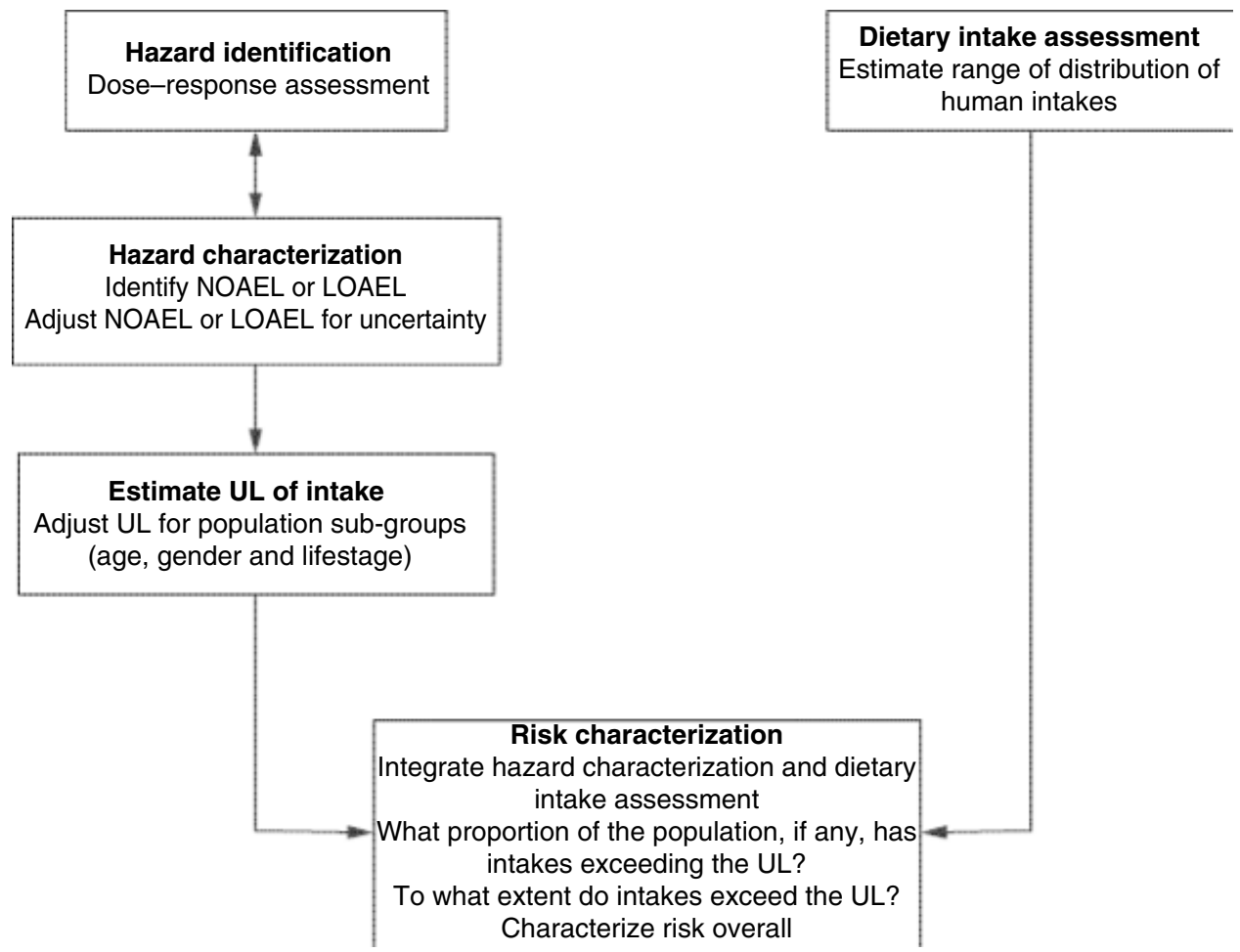

Fig. 1. Model for nutrient risk assessment and estimation of upper safe levels (UL) as recommended in the joint WHO/FAO report ${ }^{(114)}$. NOAEL, no observed adverse effect level; LOAEL, lowest observed adverse effect level.

use of human, animal and in vitro data. Studies are rated according to quality and tabulated to summarise the data. A key point in the assessment process is the selection of the critical adverse health effect, which focuses on identifying the effect associated with a level of intake most likely to provide public health protection. In practice, this effect would usually be the adverse health effect that occurs at the lowest level of intake within the population or subpopulation of interest.

\section{Dose-response relationship}

The next stage is to assess the dose-response relationship for the critical adverse health effect, which includes the determination of a no observed adverse effect level (NOAEL; (i.e. the highest intake of a nutrient at which no adverse effects have been observed) or, alternatively, a lowest observed adverse effect level (LOAEL; i.e. the lowest intake of a nutrient at which an adverse effect has been demonstrated; Fig. 2). For example, the US Food and Nutrition Board set a NOAEL of $200 \mathrm{mg}$ for vitamin $\mathrm{B}_{6}$ because according to its interpretation of the literature this level is the highest intake of vitamin $B_{6}$ at which no peripheral neuritis has been observed ${ }^{(109)}$. For $\beta$-carotene the UK EVM set a LOAEL of $20 \mathrm{mg}$ because it considered this level to be the lowest intake of $\beta$-carotene at which an increased risk of cancer has been observed in smokers ${ }^{(34)}$. In some instances authorities have considered that it was not possible to set a NOAEL or a LOAEL. For example, the UK EVM has not set either a NOAEL or a LOAEL for
$\mathrm{Mg}^{(34)}$. Studies reporting mild diarrhoea in a small percentage of healthy subjects at doses of $384-470 \mathrm{mg} / \mathrm{d}$ were used as evidence to set a guidance UL of $400 \mathrm{mg}$ supplemental $\mathrm{Mg} / \mathrm{d}$.

\section{Uncertainty}

Following the determination of a NOAEL or LOAEL, account is taken of uncertainties (e.g. those associated with extrapolating data from a small number of subjects, a short-term study, subjects with clinical disease or animal studies to the general healthy population). Estimation of $\mathrm{UL}$ is associated with a large extent of uncertainty because of the paucity of well-designed studies intended to determine the risk of nutrient intake. However, if the available data allow, a quantitative adjustment for uncertainties is made to the value (i.e. NOAEL or LOAEL) derived from the dose-response assessment. As a LOAEL is a lessrobust value than a NOAEL, a larger uncertainty value tends to be ascribed to a LOAEL. These uncertainty considerations are also checked against the level of recommended intake relative to biological essentiality or the levels of intake associated with demonstrable health benefits. After uncertainties have been taken into account, the resulting value is the UL for the nutrient concerned in the specified population or subpopulation.

$$
\mathrm{UL}=\frac{\text { NOAEL }(\text { or LOAEL) }}{\text { uncertainty factor }} \text {. }
$$




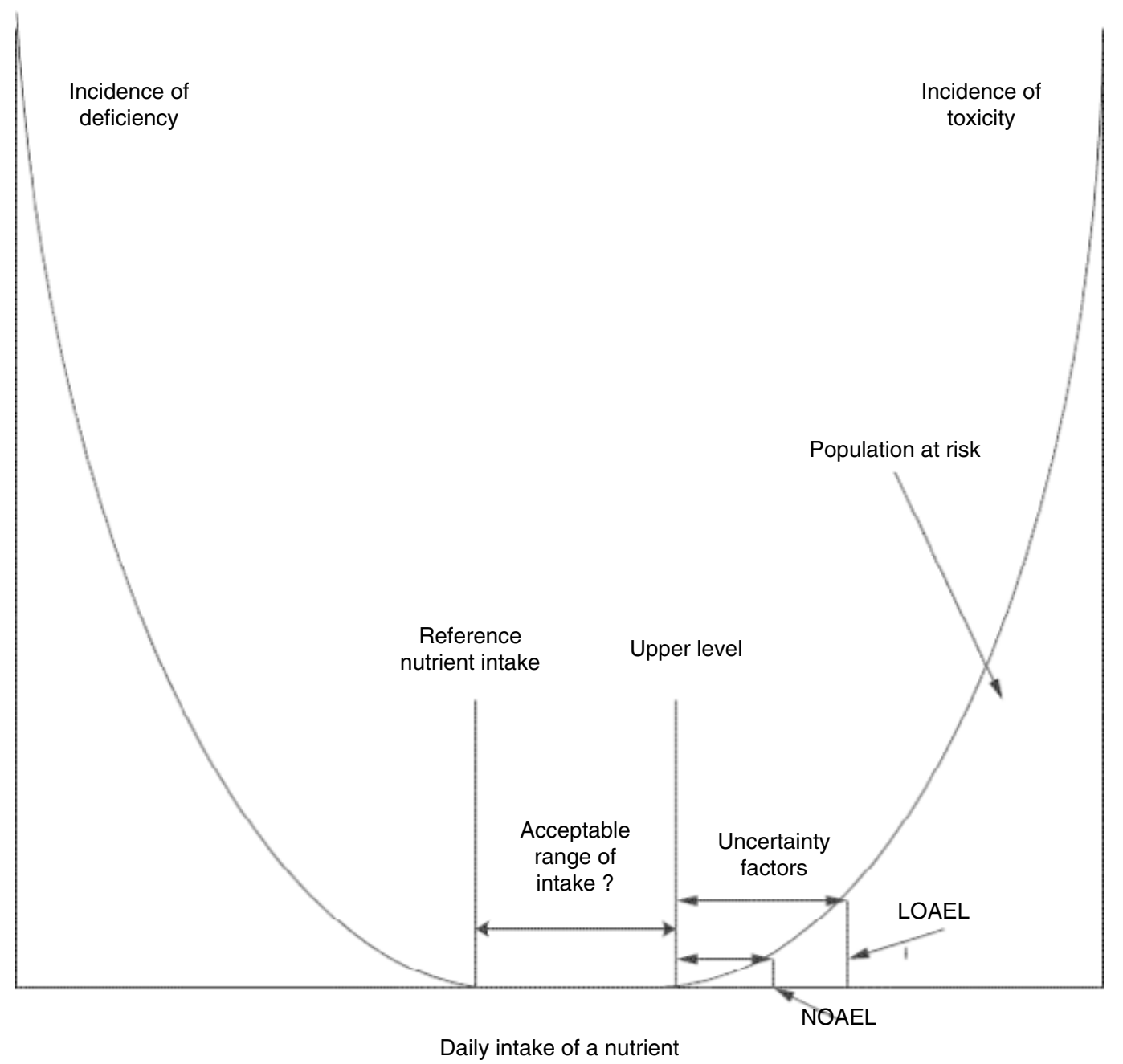

Fig. 2. Relationship between no observed adverse effect level (NOAEL), lowest observed adverse effect level (LOAEL) and upper level for a nutrient.

\section{Dietary risk assessment}

The next stage of nutrient risk assessment is dietary intake assessment (i.e. habitual dietary intake among individuals within the population), which is then combined with the outcomes of the hazard characterisation to describe the overall nature of the risk and its magnitude. Characterisation of risk includes a description of the scientific uncertainties and calculation of the margin between the RDA or actual intake and UL. Subgroups of the population with distinct sensitivities to certain nutrients (e.g. patients with haemochromatosis may be sensitive to high intakes of vitamin C) should also be considered.

\section{Differences in upper levels}

Table 1 shows that there are differences in the current UL set by the different authorities. There are two main reasons for this variation. First, some countries (e.g. the EU, USA and Australia and New Zealand) have set UL to cover the total intake from food and food supplements while others (e.g. the UK) have set UL for intake from supplements only, although the UK EVM has also set separate levels for some nutrients to include intake from food and supplements. Moreover, the UK EVM distinguishes between nutrients for which it considered there was sufficient evidence to set a UL and those for which it considered evidence was less robust and therefore set guidance levels only.

Second, different data, or different interpretations of the same data, have in some cases been used to set UL. For some nutrients this disparity occurred only because the values were based on the published studies available when the reports were being prepared. Thus, the UL for vitamin A set by the EU and the USA are higher than that set by the UK EVM because some studies showing a link between high vitamin A intakes and risk of fracture had not been published when the EU and USA set their safety limits. In the case of vitamin $B_{6}$ the UK EVM considered the available human data to be inadequate so it set a LOAEL of $50 \mathrm{mg} / \mathrm{kg}$ body weight per $\mathrm{d}$ and an uncertainty factor of 300 based on animal studies that produced a UL of $10 \mathrm{mg} / \mathrm{d}$. By contrast, both the EU and USA used human data, but even their authorities also came to different 
Table 1. Upper safety limits for vitamins and minerals set by various authorities

\begin{tabular}{|c|c|c|c|c|c|c|}
\hline \multirow[b]{2}{*}{ Vitamin or mineral } & \multicolumn{6}{|c|}{ Authorities } \\
\hline & EU RDA ${ }^{(112)}$ & CRN/EHPM ${ }^{(107)}$ & EVM UK $^{(34)}$ & FNB USA ${ }^{(108-111)}$ & SCF EU ${ }^{(124)}$ & $\mathrm{AUS} / \mathrm{NZ}^{(113)}$ \\
\hline Vitamin A (retinol equivalent; $\mu \mathrm{g}$ ) & 800 & 2300 & $1500^{*}$ & 3000 & 3600 & 3000 \\
\hline$\beta$-Carotene $(\mathrm{mg})$ & - & 20 & $7 \dagger$ & - & 20 & - \\
\hline Vitamin D (cholecalciferol; $\mu \mathrm{g}$ ) & 5 & 10 & $25^{*}$ & 50 & 50 & 80 \\
\hline Vitamin E (tocopherol; mg) & 10 & 800 & $727 \dagger$ & 1000 & 300 & 300 \\
\hline Vitamin $\mathrm{K}(\mu \mathrm{g})$ & - & - & $1000^{*}$ & - & - & - \\
\hline Thiamine (mg) & $1 \cdot 4$ & 100 & $100^{*}$ & - & - & - \\
\hline Riboflavin (mg) & $1 \cdot 6$ & 200 & $100^{*}$ & - & - & - \\
\hline Vitamin $\mathrm{B}_{6}$ (pyridoxine; mg) & 2 & 100 & $10 \dagger$ & 100 & 25 & 50 \\
\hline Vitamin $B_{12}($ cobalamin; $\mu \mathrm{g})$ & 1 & 3000 & $1000^{*}$ & - & - & - \\
\hline Niacin $(\mathrm{mg})$ & 18 & 150 & - & 35 & - & - \\
\hline Nicotinamide (mg) & - & 900 & $500^{*}$ & - & 900 & 900 \\
\hline Nicotinic acid (mg) & - & 10 & $17^{*}$ & - & 10 & 35 \\
\hline Folic acid $(\mu \mathrm{g})$ & 200 & 400 & $1000^{*}$ & 1000 & 1000 & 1000 \\
\hline Biotin $(\mu \mathrm{g})$ & 150 & 2500 & $970^{*}$ & - & - & - \\
\hline Pantothenic acid (mg) & 6 & 1000 & $200^{*}$ & - & - & - \\
\hline Vitamin C (ascorbic acid; mg) & 60 & 2000 & $1000^{*}$ & 2000 & - & - \\
\hline $\mathrm{Ca}(\mathrm{mg})$ & 800 & 1500 & $1500^{*}$ & 2500 & 2500 & 2500 \\
\hline $\mathrm{Mg}(\mathrm{mg})$ & 300 & 300 & $400^{*}$ & 350 & 250 & 350 \\
\hline$P(m g)$ & 800 & 1500 & $250^{*}$ & 4000 & - & 4000 \\
\hline $\mathrm{Fe}(\mathrm{mg})$ & 14 & 15 & $17^{*}$ & 45 & - & 45 \\
\hline $\mathrm{Zn}(\mathrm{mg})$ & 15 & 15 & $25 \dagger$ & 40 & 25 & 40 \\
\hline $\mathrm{Cu}$ (mg) & - & 5 & $5 \dagger$ & 10 & 5 & 10 \\
\hline $\mathrm{I}(\mu \mathrm{g})$ & 150 & 500 & $500^{*}$ & 1100 & 600 & 1100 \\
\hline $\mathrm{Cr}(\mu \mathrm{g})$ & - & 200 & - & - & - & - \\
\hline $\mathrm{Mn}(\mathrm{mg})$ & - & 15 & $4^{*}$ & 11 & - & - \\
\hline Mo $(\mu \mathrm{g})$ & - & 200 & - & 2,000 & 600 & 2000 \\
\hline Se $(\mu \mathrm{g})$ & - & 200 & $200 \dagger$ & 400 & 300 & 400 \\
\hline $\mathrm{B}(\mathrm{mg})$ & - & 20 & 5.9† & 20 & 10 & - \\
\hline $\mathrm{Ni}(\mu \mathrm{g})$ & - & - & 1 & - & - & - \\
\hline $\mathrm{Va}(\mathrm{mg})$ & - & - & $1 \cdot 8$ & - & - & - \\
\hline Si (mg) & - & - & 700 & - & - & - \\
\hline
\end{tabular}

EU RDA, the RDA considered sufficient to prevent deficiency in most individuals in the population; CRN/EHPM, upper safe level defined by the European Federation of Health Product Manufacturers Association and the UK Council for Responsible Nutrition as daily intakes from supplements that could be consumed on a long-term basis; EVM UK, values produced by the UK Expert Vitamin and Mineral Group; FNB USA, tolerable upper intake levels defined by the Food and Nutrition Board of the US National Academy of Sciences as the highest total level of a nutrient (diet plus supplements) that could be consumed safely on a daily basis that is unlikely to cause adverse health effects to almost all individuals in the general population. As intakes rise above the upper level, the risk of adverse effects increases. The upper level describes long-term intakes, so that an isolated dose above the upper level need not necessarily cause adverse effects. The upper level defines safety limits and is not a recommended intake for most of the population most of the time; SCF EU, tolerable upper intake levels defined by the EC Scientific Committee on Food as the maximum level of chronic daily intake of a nutrient (from all sources) judged to be unlikely to pose a risk of adverse effects to human subjects; AUS/NZ, upper levels of intake for vitamins and minerals in adult men and women.

*Likely safe total daily intake from supplements alone.

†Safe upper level from supplements alone.

conclusions. The EU set a LOAEL of $100 \mathrm{mg}$, an uncertainty factor of 4 and a UL of $25 \mathrm{mg} / \mathrm{d}$, while the USA set a NOAEL of $200 \mathrm{mg}$, an uncertainty factor of 2 and a UL of $100 \mathrm{mg} / \mathrm{d}$.

UL should be reviewed regularly in line with emerging data. An argument is already being made to increase the current US UL for vitamin D from $50 \mu \mathrm{g}$ to $250 \mu \mathrm{g}$ (and also increase the dietary reference intake from $10 \mu \mathrm{g} / \mathrm{d}$ to 25 or $50 \mu \mathrm{g}$ ) on the basis of its emerging public health benefits $^{(115)}$.

\section{Maximum permitted levels of vitamins and minerals in food supplements}

The European Commission Food Supplements Directive ${ }^{(1)}$ recognises that consistently-high total intakes of some vitamins and minerals may result in adverse effects and makes provisions for setting maximum permitted levels (MPL) of vitamins and minerals in food supplements. MPL should be distinguished from UL, which are in some cases upper levels for total intake and have no legal bearing on the vitamin and mineral content of food supplements.

The Directive also states that in setting MPL, 'account should be taken of ULs, as established by scientific risk assessment, based on generally acceptable scientific data, and of intakes of these nutrients from the normal diet'. The UL for vitamins and minerals determined by the EVM and in the EU are based on scientific risk assessment and not dietary need, and could therefore be used to establish MPL for supplements across the EU. The Directive also states that 'due account should be taken of reference intake amounts, which is the amount considered necessary to ensure nutritional sufficiency'. However, intakes of vitamins and minerals from the diet vary across member states, 
Table 2. Categorisation of vitamins and minerals based on risk according to the model developed by European Responsible Nutrition Alliance and European Federation Association of Health Product Manufacturers

\begin{tabular}{|c|c|c|c|c|}
\hline \multirow{2}{*}{$\begin{array}{l}\text { A. No evidence of risk } \\
\text { within ranges currently } \\
\text { consumed (no UL) } \\
\text { Thiamine }\end{array}$} & \multicolumn{2}{|c|}{$\begin{array}{l}\text { B. Low risk of exceeding } \\
\text { the UL: PSI }\end{array}$} & \multicolumn{2}{|c|}{$\begin{array}{c}\text { C. Potential risk at excessive } \\
\text { intakes: PSI }\end{array}$} \\
\hline & Nicotinamide & $52 \cdot 8$ & $\mathrm{Fe}$ & 1.5 \\
\hline Riboflavin & Vitamin E & $23 \cdot 2$ & I & $1 \cdot 1$ \\
\hline Biotin & Vitamin C & $22 \cdot 0$ & $\mathrm{Cu}$ & 0.8 \\
\hline Vitamin $B_{12}$ & Vitamin $\mathrm{B}_{6}$ & $21 \cdot 9$ & $\mathrm{Ca}$ & 0.6 \\
\hline Pantothenic acid & Vitamin D & $8 \cdot 1$ & $\mathrm{Zn}$ & 0.4 \\
\hline Vitamin K & Mo & $7 \cdot 4$ & $\mathrm{Mn}$ & \\
\hline \multirow[t]{2}{*}{$\mathrm{Cr}$} & $\mathrm{Se}$ & $3 \cdot 6$ & $\begin{array}{l}\text { Vitamin A } \\
\quad \text { (preformed retinol) }\end{array}$ & $-1 \cdot 2$ \\
\hline & $P$ & $2 \cdot 1$ & & \\
\hline
\end{tabular}

UL, upper intake level; PSI, population safety index.

and between communities within a member state, because of differing food habits, which will lead to problems in agreeing MPL for supplements intended to apply across the EU.

\section{Models for setting maximum permitted levels in supplements}

Several models have been put forward for setting MPL in food supplements, including the risk-management model of the European Responsible Nutrition Alliance/European Federation Association of Health Product Manu-

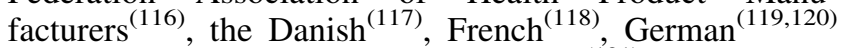
and International Life Science Institute ${ }^{(121)}$ models. The Danish, French and International Life Science Institute models focus on amounts of nutrients for addition to conventional foods (i.e. food fortification) and will not be considered further here.

\section{European Responsible Nutrition Alliance/European Federation Association of Health Product Manufacturers model}

This model works by dividing vitamins and minerals into three categories of risk by estimating the potential of population groups with higher levels of intake to exceed the UL. This potential is known as the population safety index (PSI), which is characterised as follows:

$$
\mathrm{PSI}=\frac{\mathrm{UL}-(\mathrm{MHI}+\mathrm{IW})}{\mathrm{RLV}},
$$

where $\mathrm{MHI}$ is the mean highest intake from dietary sources $(97 \cdot 5$ th percentile of the average male adult intake from studies undertaken in Ireland, Italy, The Netherlands and the UK), IW is the potential intake from water, RLV is the reference labelling value (developed by the EU Scientific Committee on Food and equivalent to the RDA).

This model has produced cut-off values for PSI, such that where the PSI is $>1.5$ (i.e. where the difference between the current highest intake from food and the UL is
$>150 \% \times \mathrm{RLV})$ the chance of exceeding the UL through supplementation is considered to be extremely low. Where PSI is $\leq 1.5$ (i.e. where the difference between the current highest intake from food and the UL is $<150 \% \times \mathrm{RLV}$ ) supplementation may potentially lead to intakes that approach the UL. The cut-off of 1.5 is based on nutrient intake data from the UK and Germany that indicate that supplements contribute a maximum of $141 \%$ of the RLV to total nutrient intake.

On the basis of the evaluation of PSI for nutrients where a UL exists, and taking into account qualitative characteristics for nutrients where no UL exists, three categories of vitamins and minerals emerge with this model (see Table 2).

MPL, or maximum safe levels (MSL) as they are termed in this model, are then set as follows (see Table 3):

group A nutrients: this model suggests no evidence of risk within ranges currently consumed and therefore no rationale for setting an MSL;

group B nutrients: the assumption is made that the risk of exceeding the UL on the basis of current intake is small. Taking into account intake from dietary sources (including fortified foods) and water, the model has developed equations for calculating the MSL for vitamins and minerals in this group:

$$
\begin{aligned}
& \text { for vitamins } \mathrm{MSL}=\mathrm{UL}-(\mathrm{MHI} \times 150 \%) \\
& \text { for minerals } \mathrm{MSL}=\mathrm{UL}-((\mathrm{MHI} \times 110 \%)+\mathrm{IW})
\end{aligned}
$$

group C nutrients: there is a narrow range of safety, so MSL are calculated on a case-by-case basis.

\section{The German model}

Germany's Federal Institute for Risk Assessment has made proposals for maximum levels of vitamins and minerals in food supplements and also for maximum levels for the fortification of conventional foods ${ }^{(119,120)}$ (Table 3$)$. In this model the amount of each nutrient that can be added to the diet as a whole with no appreciable risk of adverse health effects is determined as the difference between the 
Table 3. Examples of maximum supplement levels proposed by different models

\begin{tabular}{|c|c|c|}
\hline & ERNA/EHPM $^{(116)}$ & $\mathrm{BfR}^{(119,120)}$ \\
\hline Vitamin A $(\mu \mathrm{g})$ & $800-1000$ & $400 \dagger$ \\
\hline$\beta$-Carotene $(\mathrm{mg})$ & $4 \cdot 8-7$ & 2 \\
\hline Vitamin D $(\mu \mathrm{g})$ & 35 & $5 \ddagger$ \\
\hline Vitamin E (mg) & $270-970$ & 15 \\
\hline Vitamin K $(\mu \mathrm{g})$ & $-^{\star}$ & 80 \\
\hline Thiamine (mg) & $-^{\star}$ & 4 \\
\hline Riboflavin (mg) & $-^{*}$ & $4 \cdot 5$ \\
\hline Vitamin $B_{6}(\mathrm{mg})$ & $18-93$ & $5 \cdot 4$ \\
\hline Vitamin $B_{12}(\mu \mathrm{g})$ & $-{ }^{*}$ & $3-9$ \\
\hline Nicotinamide (mg) & 820 & 17 (niacin)§ \\
\hline Folic acid $(\mu \mathrm{g})$ & 600 & 400 \\
\hline Biotin $(\mu \mathrm{g})$ & $-^{\star}$ & 180 \\
\hline Pantothenic acid (mg) & $-{ }^{*}$ & 18 \\
\hline Vitamin C (mg) & 1750 & 225 \\
\hline $\mathrm{Ca}(\mathrm{mg})$ & $1000-1500$ & 500 \\
\hline $\mathrm{Mg}(\mathrm{mg})$ & 250 & 250 \\
\hline$P(\mathrm{mg})$ & 1250 & 250 \\
\hline $\mathrm{Fe}(\mathrm{mg})$ & $14-20$ & 0 \\
\hline $\mathrm{Zn}(\mathrm{mg})$ & $10-15$ & $2 \cdot 25 \|$ \\
\hline $\mathrm{Cu}(\mathrm{mg})$ & $1-2$ & 0 \\
\hline$(\mu \mathrm{g})$ & $150-200$ & 100 \\
\hline $\mathrm{Cr}(\mu \mathrm{g})$ & $-^{\star}$ & 60 \\
\hline $\mathrm{Mn}(\mathrm{mg})$ & 2 & 0 \\
\hline Mo $(\mu \mathrm{g})$ & 350 & 809 \\
\hline $\mathrm{Se}(\mu \mathrm{q})$ & 200 & $25-30$ \\
\hline
\end{tabular}

ERNA, European Responsible Nutrition Alliance; EHPM, European

Federation Association of Health Product Manufacturers; BfR, German

Federal Institute for Risk Assessment, proposed maximum levels in food supplements.

*Level not set because ERNA/EHPM model considers no evidence of risk at current intakes.

†200 $\mu \mathrm{g}$ for children aged between 4 and 10 years.

$\ddagger 10 \mu \mathrm{g}$ for adults $>65$ years of age.

$\S$ No use of nicotinic acid.

$\|$ No supplements for children or adolescents aged $<18$ years.

ФMaximum level not suitable for children aged $<11$ years.

UL and the current estimated intake of the respective micronutrients from non-fortified foods at percentile 95 or $97 \cdot 5$.

$$
\text { Thus, } \mathrm{R}=\mathrm{UL}-\mathrm{DINF} \text {, }
$$

where $\mathrm{R}$ is the residual amount available for addition to supplements or fortified foods, DINF is the current estimated level of intake of a micronutrient from nonfortified food at percentile 95 or $97 \cdot 5$. R constitutes the tolerable intake of a vitamin or mineral via food supplements plus the tolerable intake via fortified foods. The percentage of $\mathrm{R}$ available for addition to supplements or fortified foods is selectable and may vary between 0 and $100 \%$, but the sum of the two percentages may not exceed $100 \%$.

Considering that individuals may take more than one supplement or consume several portions of fortified food daily, a multiple-exposure factor has been introduced, and maximum levels for single-portion supplements or foods calculated. For nutrients with large margins between the UL and the 95th or 97.5th percentile of intake (e.g. folic acid) this large residual amount is divided into equal parts between food supplements and fortified foods. In the case of nutrients with small margins (e.g. Zn) the available (small) residual amount is allocated to food supplements only with no fortification of conventional foods permitted. Maximum amounts calculated for addition to supplements are shown in Table 3. In assuming the daily consumption of two food supplements and two fortified foods containing nutrients at the maximum level, this model derives maximum amounts of food supplements that are lower than those of the European Responsible Nutrition Alliance/ European Federation Association of Health Product Manufacturers model.

\section{European Commission discussion paper}

In 2006 the European Commission published a discussion paper on the setting of maximum and minimum amounts for vitamins and minerals in foodstuffs, including food supplements ${ }^{(122)}$. Responses from EU member states and various stakeholders have been published on the Europa website $^{(123)}$. These responses represent a range of viewpoints on questions such as whether MPL should be set for vitamins and minerals for which risk of adverse effects seems to be low or non-existent even at high levels of intake, with some suggesting there is no need for the setting of MPL while others maintain that MPL should be set for all vitamins and minerals. Views also differ on whether separate levels are needed for food supplements and fortified foods and whether different MPL should be set for different population groups. The question of whether RDA should be taken into account when setting MPL is also being discussed, but the majority view is that RDA should not play a major role and that MPL should be based on risk assessment. The European Commission plans to put forward proposed levels for agreement by the member states in the Standing Committee on the Food Chain, but it is unlikely to happen before 2008 .

When the levels are set, they will apply across the EU. For countries such as the UK, the Republic of Ireland and The Netherlands, which have traditionally had a liberal policy on the sale of supplements and the doses they contain, there is a concern that products would disappear from the market, limiting consumer choice. What may be possible, although it is as yet unclear, is that individual member states may be permitted to set higher MPL for products sold only in that member state.

Thus, the UK Food Standards Agency has suggested three options:

option 1 would be to establish one maximum level for each vitamin and mineral in supplements throughout the EU, taking into account available data on the highest intake from dietary sources for each vitamin and mineral across member states. This approach would be in line with the single market intention of the Directive but would be excessively precautionary and restrict consumer choice;

option 2 would be to establish common MSL for vitamins and minerals as in option 1, but with higher national maximum levels where there is evidence that dietary levels at a national level are lower than the amount used in option 1 or a national expert opinion supported safe supplemental intakes. This option would 
protect consumer safety throughout the EU, trade would be allowed across the EU for vitamins and minerals at an agreed level and UK consumer choice would be largely maintained. However, the Directive makes no mention of member states being able to set levels on a national basis so there is considerable uncertainty as to whether it would be allowable without an amendment being made;

option 3 would follow the same approach as option 2 except that national MPL would be replaced by national guidance levels. Like option 2, this approach would allow common MSL for the purposes of intracommunity trade across the EU but would also allow single-dose supplements that exceeded these levels to be sold at the discretion of national governments provided they carried warning labels. This option is the one recommended by the Food Standards Agency for the UK.

\section{Conclusions}

Food supplements have become increasingly popular and almost half the UK population takes them. Moderate-RDA multivitamins are amongst the most-frequently-consumed supplements, and although they are not a substitute for a poor diet, they can help to bridge nutritional gaps. Epidemiological evidence also suggests that users of multivitamins may be at lower risk of developing some conditions, e.g. CVD and cancer, than individuals who do not take such supplements. Evidence for benefit for single or combination nutrients at higher doses is inconsistent apart from some exceptions, e.g. folic acid in the prevention of neural-tube defects and $\mathrm{Ca}$ with vitamin $\mathrm{D}$ in the prevention of fracture in the institutionalised elderly. However, many intervention trials have not evaluated biomarkers, and it is difficult to be certain that appropriate combinations and doses of nutrients and appropriate durations of study have been used in these trials. With this increased popularity of food supplements and the likelihood of taking more than one product and/or high-dose products, the possibility of overdosing on supplements has become an area of concern. Several authorities have set safe UL for vitamins and minerals and the EU is in the process of setting maximum levels for vitamins and minerals in food supplements, probably by the end of 2008. Such measures should help to ensure consumer safety.

\section{References}

1. European Commission (2002) Directive 2002/46/EC of the European Parliament and of the Council on 10 June 2002 on the approximation of the laws of the Member States relating to food supplements. http://europa.eu.int/eur-lex/pri/en/oj/ dat/2002/1_183/1_18320020712en00510057.pdf

2. Henderson L, Irving K, Gregory J, Bates CJ, Prentice A, Perks J, Swan G \& Farron M (2003) The National Diet and Nutrition Survey: Adults Aged 19 to 64 Years. vol. 3: Vitamin and Mineral Intake and Urinary Analytes. London: The Stationery Office.
3. Information Resources Inc. (2005) IRI 2005 OTC Market Size statistics. http://www.pagb.co.uk/pagb/downloads/ marketinformation/FINAL \% 20IRI\%202005\%200TC\% 20Data\%20for\%20PAGB.pdf (accessed May 2007)

4. Office of Population Censuses and Surveys Social Survey Division and Department of Health (1995) The National Diet and Nutrition Survey: Children Aged $1 \frac{1}{2}$ to $4 \frac{1}{2}$ Years. London: H. M. Stationery Office.

5. Office for National Statistics Social Survey Division (2000) National Diet and Nutrition Survey: Young People Aged 4 to 18 Years. London: The Stationery Office.

6. Ministry of Agriculture Fisheries and Food (1998) National Diet and Nutrition Survey. People Aged 65 Years and Over. Report of the Diet and Nutrition Survey. London: H. M. Stationery Office.

7. Bader N, Bosy-Westphal A, Koch A \& Mueller MJ (2006) Influence of vitamin $\mathrm{C}$ and $\mathrm{E}$ supplementation on oxidative stress induced by hyperbaric oxygen in healthy men. Ann Nutr Metab 50, 173-176.

8. Kiely M, Flynn A, Harrington KE, Robson PJ, O'Connor N, Hannon EM, O'Brien MM, Bell S \& Strain JJ (2001) The efficacy and safety of nutritional supplement use in a representative sample of adults in the North/South Ireland Food Consumption Survey. Public Health Nutr 4, 10891097.

9. Beitz R, Mensink GB, Fischer B \& Thamm M (2002) Vitamins - dietary intake and intake from dietary supplements in Germany. Eur J Clin Nutr 56, 539-545.

10. Schwarzpaul S, Strassburg A, Luhrmann PM \& NeuhauserBerthold M (2006) Intake of vitamin and mineral supplements in an elderly German population. Ann Nutr Metab 50, $155-162$.

11. Archer SL, Stamler J, Moag-Stahlberg A, Van Horn L, Garside D, Chan Q, Buffington JJ \& Dyer AR (2005) Association of dietary supplement use with specific micronutrient intakes among middle-aged American men and women: the INTERMAP Study. J Am Diet Assoc 105, 1106-1114.

12. Troppmann L, Gray-Donald K \& Johns T (2002) Supplement use: is there any nutritional benefit? $J$ Am Diet Assoc 102, 818-825.

13. Briefel R, Hanson C, Fox MK, Novak T \& Ziegler P (2006) Feeding Infants and Toddlers Study: do vitamin and mineral supplements contribute to nutrient adequacy or excess among US infants and toddlers? J Am Diet Assoc 106, Suppl. 1, S52-S65.

14. Fox MK, Reidy K, Novak T \& Ziegler P (2006) Sources of energy and nutrients in the diets of infants and toddlers. $J$ Am Diet Assoc 106, Suppl. 1, S28-S42.

15. Dwyer JT, Garcea AO, Evans M, Li D, Lytle L, Hoelscher D, Nicklas TA \& Zive M (2001) Do adolescent vitaminmineral supplement users have better nutrient intakes than nonusers? Observations from the CATCH tracking study. $J$ Am Diet Assoc 101, 1340-1346.

16. Kim SH, Han JH \& Keen CL (2001) Vitamin and mineral supplement use by healthy teenagers in Korea: motivating factors and dietary consequences. Nutrition 17, 373-380.

17. Sichert-Hellert W, Wenz G \& Kersting M (2006) Vitamin intakes from supplements and fortified food in German children and adolescents: results from the DONALD study. J Nutr 136, 1329-1333.

18. Stang J, Story MT, Harnack L \& Neumark-Sztainer D (2000) Relationships between vitamin and mineral supplement use, dietary intake, and dietary adequacy among adolescents. J Am Diet Assoc 100, 905-910.

19. Girodon F, Blache D, Monget AL, Lombart M, BrunetLecompte P, Arnaud J, Richard MJ \& Galan P (1997) Effect 
of a two-year supplementation with low doses of antioxidant vitamins and/or minerals in elderly subjects on levels of nutrients and antioxidant defense parameters. $J \mathrm{Am}$ Coll Nutr 16, 357-365.

20. Navarro M \& Wood RJ (2003) Plasma changes in micronutrients following a multivitamin and mineral supplement in healthy adults. J Am Coll Nutr 22, 124-132.

21. Wolters M, Hermann S \& Hahn A (2004) Effects of 6month multivitamin supplementation on serum concentrations of alpha-tocopherol, beta-carotene, and vitamin C in healthy elderly women. Int J Vitam Nutr Res 74, 161168.

22. Rimm EB, Willett WC, Hu FB, Sampson L, Colditz GA, Manson JE, Hennekens C \& Stampfer MJ (1998) Folate and vitamin B6 from diet and supplements in relation to risk of coronary heart disease among women. JAMA 279, 359364.

23. Holmquist C, Larsson S, Wolk A \& de Faire U (2003) Multivitamin supplements are inversely associated with risk of myocardial infarction in men and womenStockholm Heart Epidemiology Program (SHEEP). J Nutr 133, 2650-2654.

24. Jacobs EJ, Connell CJ, Chao A, McCullough ML, Rodriguez C, Thun MJ \& Calle EE (2003) Multivitamin use and colorectal cancer incidence in a US cohort: does timing matter? Am J Epidemiol 158, 621-628.

25. Stevens VL, McCullough ML, Diver WR, Rodriguez C, Jacobs EJ, Thun MJ \& Calle EE (2005) Use of multivitamins and prostate cancer mortality in a large cohort of US men. Cancer Causes Control 16, 643-650.

26. Giovannucci E, Rimm EB, Ascherio A, Stamfer MJ, Colditz GA \& Willett WC (1995) Alcohol, low methionine, low folate diets and risk of colon cancer in men. $J$ Natl Cancer Inst 87, 265-273.

27. Giovannucci E, Stampfer MJ, Colditz GA, Hunter DJ, Fuchs C, Rosner BA, Speizer FE \& Willett WC (1998) Multivitamin use, folate and colon cancer in women in the Nurses' Health Study. Ann Intern Med 129, 517-524.

28. Cho E, Hunter DJ, Spiegelman D, Albanes D, Beeson WL, van den Brandt PA et al. (2006) Intakes of vitamins A, C and $\mathrm{E}$ and folate and multivitamins and lung cancer: a pooled analysis of 8 prospective studies. Int J Cancer 118, 970-978.

29. Kuzniarz M, Mitchell P, Cumming RG \& Flood VM (2001) Use of vitamin supplements and cataract: the Blue Mountains Eye Study. Am J Ophthalmol 132, 19-26.

30. Leske MC, Chylack LT Jr, He Q, Wu SY, Schoenfeld E, Friend J \& Wolfe J (1998) Antioxidant vitamins and nuclear opacities: the longitudinal study of cataract. Ophthalmology 105, 831-836.

31. El-Kadiki A \& Sutton AJ (2005) Role of multivitamins and mineral supplements in preventing infections in elderly people: systematic review and meta-analysis of randomised controlled trials. $\mathrm{Br}$ Med J 330, 871-873.

32. Stephen AI \& Avenell A (2006) A systematic review of multivitamin and multimineral supplementation for infection. J Hum Nutr Diet 19, 179-190.

33. Harrison RA, Holt D, Pattison DJ \& Elton PJ (2004) Are those in need taking dietary supplements? A survey of 21 923 adults. Br J Nutr 91, 617-623.

34. Expert Group on Vitamins and Minerals (2003) Safe Upper Levels for Vitamins and Minerals. London: Food Standards Agency; available at http://www.food.gov.uk/multimedia/ pdfs/vitmin2003.pdf

35. Food Standards Agency (2006) Survey to assess the market for high dose vitamin and mineral supplements in the UK and to determine the use of voluntary advisory statements.
Food Survey Information Sheet 12/06. http://www.food. gov.uk/multimedia/pdfs/fsis1206.pdf (accessed May 2007)

36. Fletcher RH \& Fairfield KM (2002) Vitamins for chronic disease prevention in adults: clinical applications. JAMA 287, 3127-3129.

37. Pitkin RM (2007) Folate and neural tube defects. Am J Clin Nutr 85, 285S-288S.

38. Homocysteine Lowering Trialists' Collaboration (2005) Dose-dependent effects of folic acid on blood concentrations of homocysteine: a meta-analysis of the randomized trials. Am J Clin Nutr 82, 806-812.

39. Alfthan G, Aro A \& Gey KF (1997) Plasma homocysteine and cardiovascular disease mortality. Lancet 349, 397.

40. Toole JF, Malinow MR, Chambless LE, Spence JD, Pettigrew LC, Howard VJ, Sides EG, Wang CH \& Stampfer M (2004) Lowering homocysteine in patients with ischemic stroke to prevent recurrent stroke, myocardial infarction, and death: the Vitamin Intervention for Stroke Prevention (VISP) randomized controlled trial. JAMA 291, 565-575.

41. Lonn E, Yusuf S, Arnold MJ, Sheridan P, Pogue J, Micks M et al. (2006) Homocysteine lowering with folic acid and B vitamins in vascular disease. N Engl J Med 354, 15671577.

42. Bonaa KH, Njolstad I, Ueland PM, Schirmer H, Tverdal A, Steigen $\mathrm{T}$ et al. (2006) Homocysteine lowering and cardiovascular events after acute myocardial infarction. $N$ Engl $J$ Med 354, 1578-1588.

43. Bairati I, Meyer F, Jobin E, Gelinas M, Fortin A, Nabid A, Brochet F \& Têtu B (2006) Antioxidant vitamins supplementation and mortality: a randomized trial in head and neck cancer patients. Int J Cancer 119, 2221-2224.

44. Rampersaud GC, Bailey LB \& Kauwell GP (2002) Relationship of folate to colorectal and cervical cancer: review and recommendations for practitioners. J Am Diet Assoc 102, 1273-1282.

45. Malouf R, Grimley Evans J \& Areosa Sastre A (2003) Folic Acid with or without Vitamin B12 for Cognition and Dementia. The Cochrane Database of Systematic Reviews 2003, issue 4, art. no. CD004514. Chichester, West Sussex: John Wiley.

46. Durga J, van Boxtel M, Schouten E, Kok F, Jolles J, Katan M \& Verhoef P (2007) Effect of 3-year folic acid supplementation on cognitive function in older adults in the FACIT trial: a randomised, double blind, controlled trial. Lancet 369, 208-216.

47. Taylor MJ, Carney SM, Goodwin GM \& Geddes JR (2004) Folate for depressive disorders: systematic review and metaanalysis of randomized controlled trials. J Psychopharmacol 18, 251-256.

48. Douglas RM, Hemila H, Chalker EB, D'Souza RRD \& Treacy B (2004) Vitamin C for Preventing and Treating the Common Cold. The Cochrane Database of Systematic Reviews 2004, issue 4. art no. CD000980. Chichester, West Sussex: John Wiley.

49. Sasazuki S, Sasaki S, Tsubono Y, Okubo S, Hayashi M \& Tsugane S (2005) Effect of vitamin C on common cold: randomized controlled trial. Eur J Clin Nutr 60, 9-17.

50. Ford L, Graham V, Wall A \& Berg J (2006) Vitamin D concentrations in an UK inner-city multicultural outpatient population. Ann Clin Biochem 43, 468-473.

51. Vieth R (2005) The role of vitamin D in the prevention of osteoporosis. Annals of Medicine 37, 278-285.

52. Bischoff-Ferrari H, Willett WC, Wong J, Giovannucci E, Dietrich T \& Dawson-Hughes B (2005) Fracture prevention with vitamin D supplementation: a meta-analysis of randomized controlled trials. JAMA 293, 2257-2264. 
53. Izaks GJ (2007) Fracture prevention with vitamin D supplementation: considering the inconsistent results. BMC Musculoskelet Disord 8, 26.

54. Bischoff-Ferrari H, Dawson-Hughes B, Willett W, Staehelin $\mathrm{H}$, Bazemore M, Zee R \& Wong JB (2004) Effect of vitamin D on falls: a meta-analysis. JAMA 291, 19992006.

55. Jackson C, Gaugris S, Sen SS \& Hosking D (2007) The effect of cholecalciferol (vitamin D3) on the risk of fall and fracture: a meta-analysis. QJM 100, 185-192.

56. Jialal I \& Devaraj S (2005) Scientific evidence to support a vitamin $\mathrm{E}$ and heart disease health claim: Research needs. $J$ Nutr 135, 348-353.

57. Traber MG (2007) Heart disease and single-vitamin supplementation. Am J Clin Nutr 85, 293S-299S.

58. Stampfer MJ, Hennekens CH, Manson JE, Colditz GA, Rosner B \& Willett WC (1993) Vitamin E consumption and the risk of coronary disease in women. $N$ Engl J Med 328, 1444-1449.

59. Rimm EB, Stampfer MJ, Ascherio A, Giovannucci E, Colditz GA \& Willett WC (1993) Vitamin E consumption and the risk of coronary heart disease in men. $N$ Engl J Med 328, 1450-1456.

60. Stephens NG, Parsons A, Schofield PM, Kelly F, Cheeseman K \& Mitchinson MJ (1996) Randomised controlled trial of vitamin $\mathrm{E}$ in patients with coronary disease: Cambridge Heart Antioxidant Study (CHAOS). Lancet 347, 781-786.

61. Lonn E, Bosch J, Yusuf S, Sheridan P, Pogue J, Arnold JM et al. (2005) Effects of long-term vitamin E supplementation on cardiovascular events and cancer: a randomized controlled trial. JAMA 293, 1338-1347.

62. Shekelle PG, Morton SC, Jungvig LK, Udani J, Spar M, Tu $\mathrm{W}$ et al. (2004) Effect of supplemental vitamin $\mathrm{E}$ for the prevention and treatment of cardiovascular disease. J Gen Intern Med 19, 380-389.

63. Hennekens CH, Buring JE, Manson JE, Stampfer M, Rosner B, Cook NR et al. (1996) Lack of effect of long term supplementation with beta carotene on the incidence of malignant neoplasms and cardiovascular disease. New Engl J Med 334, 1145-1149.

64. Tornwall ME, Virtamo J, Korhonen PA, Virtanen MJ, Taylor PR, Albanes D \& Huttunen JK (2004) Effect of alpha-tocopherol and beta-carotene supplementation on coronary heart disease during the 6-year post-trial follow-up in the ATBC study. Eur Heart J 25, 1171-1178.

65. Heart Protection Study Collaborative Group (2002) MRC/ BHF Heart Protection Study of antioxidant vitamin supplementation in 20,536 high-risk individuals: a randomised placebo-controlled trial. Lancet 360, 23-33.

66. Waters DD, Alderman EL, Hsia J, Howard BV, Cobb FR, Rogers WJ et al. (2002) Effects of hormone replacement therapy and antioxidant vitamin supplements on coronary atherosclerosis in postmenopausal women. JAMA $\mathbf{2 8 8}$, 2432-2440.

67. Zureik M, Galan P, Bertrais S, Mennen L, Czernichow S, Blacher J, Ducimetière, P \& Hercberg S (2004) Effects of long-term daily low-dose supplementation with antioxidant vitamins and minerals on structure and function of large arteries. Arterioscler Thromb Vasc Biol 24, 1485-1491.

68. Czernichow S, Bertrais S, Blacher J, Galan P, Briançon S, Favier A, Safar M \& Hercberg S (2005) Effect of supplementation with antioxidants upon long-term risk of hypertension in the SU.VI.MAX study: association with plasma antioxidant levels. J Hypertens 23, 2013-2018.

69. Vivekananthan DP, Penn MS, Sapp SK, Hsu A \& Topol EJ (2003) Use of antioxidant vitamins for the prevention of cardiovascular disease: meta-analysis of randomized trials. Lancet 361, 2017-2023.

70. Shekelle P, Morton S, Hardy M, Coulter I, Udani J, Spar M et al. (2003) Effect of supplemental antioxidants vitamin C, vitamin $\mathrm{E}$ and co-enzyme Q10 for the prevention and treatment of cardiovascular disease. Evidence Report/ Technology Assessment no. 83. AHRQ Publication no. 030043. http://www.ahrq.gov/clinic/epcsums/antioxsum.htm

71. Bjelakovic G, Nikolova D, Gluud LL, Simonetti RG \& Gluud C (2007) Mortality in randomized trials of antioxidant supplements for primary and secondary prevention: systematic review and meta-analysis. JAMA 297, 842857.

72. Blot WJ, Li JY \& Taylor PR (1993) Nutrition intervention trials in Linxian, China: supplementation with specific vitamin/mineral combinations, cancer incidence, and disease-specific mortality in the general population. $J$ Natl Cancer Inst 85, 1483-1492.

73. The Alpha Tocopherol Beta-Carotene Cancer Prevention Study Group (1994) The effect of vitamin E and beta carotene on the incidence of lung cancer in male smokers. New Engl J Med 330, 1029-1035.

74. Greenberg ER, Baron JA, Tosteson TD, Freeman DH, Beck GJ, Bond JH et al. (1994) A clinical trial of antioxidant vitamins to prevent colorectal adenoma. New Engl J Med 331, 141-147.

75. Plummer M, Vivas J, Lopez G, Bravo JC, Peraza S, Carillo E et al. (2007) Chemoprevention of precancerous gastric lesions with antioxidant vitamin supplementation: a randomized trial in a high-risk population. J Natl Cancer Inst $\mathbf{9 9}$, 137-146.

76. Hercberg S, Galan P, Preziosi P, Bertrais S, Mennen L, Malvy D, Roussel AM, Favier A \& Briançon S (2004) The SU.VI.MAX Study: a randomized, placebo-controlled trial of the health effects of antioxidant vitamins and minerals. Arch Intern Med 164, 2335-2342.

77. Kirsch VA, Hayes RB, Mayne ST, Chatterjee N, Subar AF, Dixon LB et al. (2006) Supplemental vitamin E, betacarotene, and vitamin $\mathrm{C}$ intakes and prostate cancer risk. $J$ Natl Cancer Inst 98, 245-254.

78. Coulter I, Hardy M, Shekelle P, Morton SC, Udani J, Spar M et al. (2003) Effect of the supplemental use of antioxidants vitamin $\mathrm{C}$, vitamin $\mathrm{E}$, and the coenzyme Q10 for the prevention and treatment of cancer. Evidence Report/Technology Assessment no. 75. AHRQ Publication no. 03-E047. http://www.ahrq.gov/clinic/epcsums/ aoxcansum.htm

79. Age-Related Eye Disease Study Research Group (2001) A randomized, placebo-controlled, clinical trial of high-dose supplementation with vitamins $\mathrm{C}$ and $\mathrm{E}$ and beta-carotene for age-related cataract and vision loss: AREDS report no.9. Arch Ophthalmol 119, 1439-1452.

80. Chylack LT Jr, Brown NP, Bron A, Hurst M, Köpcke W, Thien U \& Schalch W (2002) The Roche American Cataract Trial (REACT), a randomised clinical trial to investigate the efficacy of an oral antioxidant micronutrient mixture to slow progression of age-related cataract. Ophthalmic Epidemiol 9, 49-80.

81. Age-Related Eye Disease Study Research Group (2001) A randomized, placebo-controlled, clinical trial of high-dose supplementation with vitamins $\mathrm{C}$ and $\mathrm{E}$, beta-carotene and zinc for age-related cataract and vision loss: AREDS report no.8. Arch Ophthalmol 119, 1417-1436.

82. Winzenberg T, Shaw K, Fryer J \& Jones G (2006) Effects of calcium supplementation on bone density in healthy children: meta-analysis of randomised controlled trials. $\mathrm{Br}$ Med J 333, 775. 
83. Shea B, Wells G, Cranney A, Moher D, Adachi R, Treleaven D, Peterson J, Tugwell P \& Henry D (2004) Calcium Supplementation on Bone Loss in Postmenopausal Women. The Cochrane Database of Systematic Reviews 2004, issue 1. art no. CD004526. Chichester, West Sussex: John Wiley.

84. Chapuy MC, Arlot ME, Duboeuf F, Brun J, Crouzet B, Arnaud S, Delmas PD \& Meunier PJ (1992) Vitamin D and calcium to prevent hip fractures in elderly women. $N$ Engl $J$ Med 327, 1637-1642.

85. Chapuy MC, Pamphile R, Paris E, Kempf C, Schlichting M, Arnaud S, Garnero P \& Meunier PJ (2002) Combined calcium and vitamin D3 supplementation in elderly women: confirmation of reversal of secondary hyperparathyroidism and hip fracture risk: the Decalyos II study. Osteporosis Int 13, 257-264.

86. Dawson-Hughes B, Harris SS, Krall EA \& Dallal GE (1997) Effect of calcium and vitamin D supplementation on bone density in men and women 65 years of age or older. $N$ Engl J Med 337, 670-676.

87. Dickinson HO, Nicolson DJ, Cook JV, Campbell F, Beyer FR, Ford GA \& Mason J (2006) Calcium Supplementation for the Management of Primary Hypertension in Adults. The Cochrane Database of Systematic Reviews 2006, issue 2. art no. CD004639. Chichester, West Sussex: John Wiley.

88. Wallace K, Baron JA, Cole BF, Sandler RS, Karagas MR, Beach MA et al. (2004) Effect of calcium supplementation on the risk of large bowel polyps. J Natl Cancer Inst 96, 921-925.

89. Weingarten MA, Zalmanovici A \& Yaphe J (2005) Dietary Calcium Supplementation for Preventing Colorectal Cancer and Adenomatous Polyps. The Cochrane Database of Systematic Reviews 2005, issue 2, art no. CD003548. Chichester, West Sussex: John Wiley.

90. Thys-Jacobs S, Ceccarelli S, Bierman A, Weisman H, Cohen MA \& Alvir J (1989) Calcium supplementation in premenstrual syndrome: a randomized crossover trial. J Gen Intern Med 4, 183-189.

91. Thys-Jacobs S, Starkey P, Bernstein D \& Tian J (1998) Calcium carbonate and the premenstrual syndrome: effects on premenstrual and menstrual symptoms (Premenstrual Syndrome Study Group). Am J Obstet Gynecol 179, 444-452.

92. Shapses SA, Heshka S \& Heymsfield SB (2004) Effect of calcium supplementation on weight and fat loss in women. J Clin Endocrinol Metab 89, 632-637.

93. Clark LC, Combs GF Jr \& Turnbill BW (1996) Effects of selenium supplementation for cancer prevention in patients with carcinoma of the skin: a randomized controlled trial: Nutritional Prevention of Cancer Study Group. JAMA 276, 1957-1963.

94. Duffield-Lillico AJ, Dalkin BL, Reid ME, Turnbull BW, Slate EH, Jacobs ET, Marshall JR, Clark LC \& Nutritional Prevention of Cancer Study Group (2003) Selenium supplementation, baseline plasma selenium status and incidence of prostate cancer: an analysis of the complete treatment period of the Nutritional Prevention of Cancer Trial. BJU Int 91, 608-612.

95. Etminan M, FitxGerald JM, Gleave $M$ \& Chambers $K$ (2005) Intake of selenium in the prevention of prostate cancer: a systematic review and meta-analysis. Cancer Causes Control 16, 1125-1131.

96. Melhus H, Michaelsson K, Kindmark A, Bergstrom R, Holmberg L, Mallmin H, Wolk A \& Ljunghall S (1998) Excessive dietary intake of vitamin A is associated with reduced bone mineral density and increased risk for hip fracture. Ann Intern Med 129, 770-778.
97. Sigurdsson G, Franzson L \& Thorgeirsdottir HLS (2001) A lack of association between excessive dietary intake of vitamin A and bone mineral density in seventy-year-old Icelandic women. In Nutritional Aspects of Osteoporosis, pp. 295-302. [P Burckhardt, B Dawson-Hughes and RP Heaney, editors]. New York: Academic Press.

98. Sowers M \& Wallace R (1990) Retinol, supplemental vita$\min \mathrm{A}$, and bone status. Journal of Clinical Epidemiology 43, 693-699.

99. Ballew C, Galuska D \& Gillespie C (2001) High serum retinyl esters are not associated with reduced bone mineral density in the third National Health and Nutrition Examination Survey, 1988-1994. J Bone Miner Res 16, 23062312.

100. Promislow J, Goodman-Gruen D, Slymen D \& BarrettConnor E (2002) Retinol intake and bone mineral density in the elderly: the Rancho Bernardo Study. J Bone Miner Res 17, 1349-1358.

101. Feskanich D, Singh V, Willett WC \& Colditz GA (2002) Vitamin A intake and hip fractures among postmenopausal women. JAMA 287, 47-54.

102. Michaelsson K, Lithell H, Vessby B \& Melhus H (2003) Serum retinol levels and the risk of fracture. $N$ Engl $J$ Med 348, 287-294.

103. Lim LS, Harnack LJ, Lazovich D \& Folsom AR (2004) Vitamin A intake and the risk of hip fracture in postmenopausal women: the Iowa Women's Health Study. Osteoporos Int 15, 552-529.

104. Barker ME, McCloskey E, Saha S, Gossiel F, Charlesworth D, Powers HJ \& Blumsohn A (2005) Serum retinoids and beta-carotene as predictors of hip and other fractures in elderly women. J Bone Miner Res 20, 913-920.

105. Rejnmark L, Vestergaard P, Charles P, Hermann AP, Brot C, Eiken P \& Mosekilde L (2004) No effect of vitamin A intake on bone mineral density and fracture risk in perimenopausal women. Osteoporos Int 15, 872-880.

106. Kawahara TN, Krueger DC, Engelke JA, Harke JM \& Binkley NC (2002) Short-term vitamin A supplementation does not affect bone turnover in men. J Nutr 132, 11691172.

107. Shrimpton D (1997) Vitamins and Minerals. A Scientific Evaluation of the Range of Safe Intakes. Thames Ditton, Surrey: Council for Responsible Nutrition.

108. Institute of Medicine Food and Nutrition Board (1999) Dietary Reference Intakes for Calcium, Phosphorus, Magnesium, Vitamin $D$ and Fluoride. Washington, DC: The National Academies Press.

109. Institute of Medicine Food and Nutrition Board (2000) Dietary Reference Intakes for Thiamin, Riboflavin, Niacin, Vitamin $B_{6}$, Folate, Vitamin $B_{12}$, Pantothenic Acid, Biotin and Choline. Washington, DC: The National Academies Press.

110. Institute of Medicine Food and Nutrition Board (2000) Dietary Reference Intakes for Vitamin C, Vitamin E, Selenium and Carotenoids. Washington, DC: The National Academies Press.

111. Institute of Medicine Food and Nutrition Board (2002) Dietary Reference Intakes for Vitamin A, Vitamin $K$, Arsenic, Boron, Chromium, Copper, Iodine, Iron, Manganese, Molybdenum, Nickel, Silicon, Vanadium and Zinc. Washington, DC: National Academies Press.

112. Scientific Committee on Food Scientific Panel on Dietetic Products, Nutrition and Allergies (2006) Tolerable upper intake levels for vitamins and minerals; available at http://www.efsa.europa.eu/etc/medialib/efsa/press_room/ publications/scientific/1497.Par.0016.File.dat/upper_level_ opinions_hi-part11.pdf (accessed May 2007) 
113. Australian Government Department of Health and Ageing, National Health and Medical Research Council and New Zealand Ministry of Health (2005) Nutrient reference values for Australia and New Zealand. http://www.nhmrc.gov.au/ publications/synopses/_files/n35.pdf

114. World Health Organization and Food and Agricultural Organization (2006) A Model for Establishing Upper Levels of Intake for Nutrients and Related Substances. Report of a Joint FAO/WHO Technical Workshop on Nutrient Risk Assessment. Geneva: WHO.

115. Hathcock JN, Shao A, Vieth R \& Heaney R (2007) Risk assessment for vitamin D. Am J Clin Nutr 85, 6-18.

116. European Responsible Nutrition Alliance and European Federation Association of Health Product Manufacturers (2004) Vitamin and Mineral Supplements: A Risk Management Model. Brussels: ERNA; available at www.ehpm.org/ GetArticle. aspx ?articleid $=29$

117. Rasmussen SE, Andersen NL, Dragsted LO \& Larsen JC (2006) A safe strategy for addition of vitamins and minerals to foods. Eur J Nutr 45, 123-135.

118. Agence Francaise de Securite Sanitaire des Aliments (2003) Cahier des charges pour le choix d'un couple nutrimentaliment vecteur (Specification for the selection of a nutrientvector food pair). http://www.afssa.fr//ftp/afssa/actu/CDC versionfinale.pdf
119. Domke A, Grossklaus R, Niemann B, Przyrembel K, Richter K, Schmidt E et al. (2005) Use of Vitamins in Foods. Toxicological and Nutritional Aspects. Part 1. Berlin: Federal Institute for Risk Assessment.

120. Domke A, Grossklaus R, Niemann B, Przyrembel K, Richter K, Schmidt E et al. (2005) Use of Minerals in Foods. Toxicological and Nutritional Aspects. Part 2. Berlin: Federal Institute for Risk Assessment.

121. Flynn A, Moreiras O, Stehle P, Fletcher R, Muller D \& Rolland V (2003) Vitamins and minerals: a model for safe addition to foods. Eur J Clin Nutr 42, 118-130.

122. European Commission Health and Consumer Protection Directorate-General (2006) Discussion paper on the setting of maximum and minimum amounts for vitamins and minerals in foodstuffs. http://ec.europa.eu/food/food/labellingnutrition/supplements/discus_paper_amount_vitamins.pdf

123. European Commission Health and Consumer Protection Directorate-General (2006) Responses to the discussion paper on the setting of maximum and minimum amounts of vitamins and minerals in foodstuffs. http://ec.europa. eu/food/food/labellingnutrition/supplements/resp_discus_ paper_amount_vitamins.htm

124. Scientific Committee on Food (2003) Tolerable upper intake levels for vitamins and minerals. http://ec.europa.eu/comm/ food/fs/sc/scf/out80_en.html 